\title{
A FACTOR ANALYTIC EXAMINATION OF THE ACHIEVEMENT GOAL QUESTIONNAIRE-REVISED SUPPORTS A THREE-FACTOR MODEL ${ }^{1}$
}

\author{
KAMDEN K. STRUNK \\ The University of Southern Mississippi
}

\begin{abstract}
Summary.-The literature in achievement goals includes mixed results as to the factor structure of achievement goal measures, particularly the Achievement Goal Questionnaire, Revised (AGQ-R). In a sample of 1,496 undergraduate students (600 men, 891 women, 5 gender unreported; $M$ age $=20.6$ yr., $S D=3.2$ ), the AGQ-R was subjected to an exploratory factor analysis that suggested three factors. Then, in a different sample of 1,125 undergraduate students ( 270 men, 750 women, 5 gender unreported; $M$ age $=21.7$ yr., $S D=5.4$ ), the measure was subjected to a confirmatory factor analysis, in which a three-factor solution, again, showed the best fit to the observed data. The implications of these results for the measurement of achievement goals are discussed.
\end{abstract}

NOTICE: This is the authors' version of a work that was published in Psychological Reports. Changes resulting from the publication process, such as peer review, editing, corrections, structural formatting, and other quality control mechanisms may not be reflected in this document. Changes may not have been made to this work since it was submitted for publication. A definitive version was subsequently published in Psychological Reports, DOI 10.2466/14.03.PR0.115c24z0

Recommended citation: Strunk, K. K. (2014). A factor analytic examination of the achievement goal questionnaire, revised: A three-factor model. Psychological Reports, 115(2), 400-414. 
Achievement goals have been of interest to educational and motivational researchers for decades. However, the nature of the construct has changed over time. In early theoretical models, achievement goals were thought to comprise a two-factor model, wherein there were essentially mastery goals and performance goals. Mastery goals were conceptualized as goals that focus on the intrinsic value associated with learning, on effort, the connection between effort and attainment, as well as a focus on development, understanding, and improving (Ames, 1992). On the other hand, performance goals were thought of as focusing on showing ability, primarily by doing better than others, so that the focus is on normative standards for success (Ames, 1992).

Goal theorists then began to differentiate the nature of achievement goals, beginning by dividing performance goals into performance approach and performance avoidance goals, alongside mastery approach goals (Elliot \& Church, 1997). This theoretical framework is commonly known as the trichotomous model, accounting for the role of motivational valence. By incorporating motivational valence, one is concerned not only with the performance aspect of the goal, but also with the direction of the goal. So a student might be concerned with performing better than his/her peers, which would be an example of a performance-approach goal, having both the qualities of performance (the focus is on showing ability) and approach (exceeding the standard or doing better than others). A student could also seek to avoid doing worse than his/her peers, which would be a performance-avoidance goal, having the same performance quality, but an avoidance valence.

Later, the $2 \times 2$ model for achievement goals was proposed, which was aimed primarily to balance the system by having both mastery and performance goals split into approach and avoidance (Elliot, 1999). This model included four distinct goals: mastery approach, mastery avoidance, performance approach, and performance avoidance. The distinction of mastery goals by valence has always been more difficult - how does one hold a mastery-avoidance goal? Elliot and Church (1997) has argued that valence is a necessary element to account for behavior and motivation, therefore valence should be included in any model of achievement goals. However, when attempting to measure goals in the $2 \times 2$ model, Elliot and Church (1997) found that only three factors emerged in an exploratory factor analysis, suggesting that mastery approach and mastery avoidance goals did not diverge.

Elliot and Thrash (2001) argued that mastery avoidance goals were likely to be more common among the elderly or athletes who have reached their peak potential. Using a different measure - the Achievement Goal Questionnaire (AGQ) - Elliot and McGregor (2001) did achieve a four-factor solution consistent with the $2 \times 2$ model. However, it is worth noting that this was accomplished using a varimax rotation, although the factors were correlated from $r=.21$ to .40 . Later, Elliot and Murayama (2008) developed and assessed the Achievement Goal Questionnaire, Revised (AGQ-R). Among their data collected from 229 college students, this measure demonstrated a good fit to the four-factor, $2 \times 2$ model in a confirmatory factor analysis. Since the development of the AGQ-R, the $2 \times 2$ model has almost completely displaced the trichotomous model in the literature. However, it is worth noting that the AGQ-R was immediately subjected to confirmatory factor analysis in its development, without an exploratory factor analysis in the original development literature (e.g., Elliot \& Murayama, 2008).

The nature of the achievement goal constructs has not been without controversy. Different researchers have pursued both the two-factor and four-factor models, but other competing models such as three-factor models have also emerged in the literature. The nature of the constructs and their structure is a matter of more than psychometric or methodological concern. The way in which the constructs are thought of, measured, operationalized, and structured has a great effect on how they relate to, predict, and correlate with other variables in subsequent analyses (Grant \& Dweck, 2003). That is, the structure of the instrument and the underlying constructs are extremely important in understanding achievement goals, students' motivation, and learning. Meaningful educational decisions are made as a result of theoretical ideas about achievement goals, their predictors, outcomes, and interrelationships. Therefore, it is important to understand the way that they are structured, how they have been measured, and what it means to talk about achievement goals in the educational literature.

The four-factor model (Elliot \& Church, 1997; Elliot \& Thrash, 2001; Elliot \& Murayama, 2008) has been the most popular measurement model for achievement goals. However, researchers have not consistently found four-factor structure for this measurement model. Attenweiler and Moore (2006) argued for a three-factor model based on their confirmatory factor analysis and model comparisons. Finney, Pieper, 
and Barron (2004) used analytic techniques similar to Attenweiler and Moore (2006), but found the fourfactor model to be the best fit for their data. Remedios, Kiseleva, and Elliott (2008) found differences in the structure of the AGQ among a sample of Russian university students as compared with what the authors of the measure had reported, though they still reported a four-factor structure. In a comparison of White and Black college students, Campbell, Barry, Joe, and Finney (2008) found that the AGQ-R showed the best fit to the data under the four-factor model, and appeared invariant among the two samples. Donnellan (2008), using exploratory methods, found a three-factor structure including learning goals, performance goals, and outcome goals. These varying results from different samples using different analytic techniques may represent a problem with the way that the AGQ-R measures or operationalizes the theoretical construct of achievement goal theory. This measure may be failing to fully capture those theoretical constructs that goal theorists have established in the literature.

Furthermore, in order to truly assess other validity evidence for the AGQ-R, such as criterion validity, it is first necessary to settle the issues of content validity and the structure of the instrument. Because previous research has presented mixed results regarding the structure of the AGQ and AGQ-R, the goal of the present study was to determine how many underlying factors would account for the variance in the set using exploratory methods, and which model would best fit the observed data using confirmatory methods. By approaching the measure with exploratory methods first, no structure is imposed on the measure, allowing for a free search for the underlying number of latent factors and interpretation of the nature of those factors. Then, by using confirmatory factor analysis in a second, comparable sample, the solution from the exploratory model can be compared to other models found in the literature for this measure. Thus, we tested the hypothesis that the Elliott and Murayama (2008) proposed four-factor model would be supported by exploratory and confirmatory factor analyses.

\section{Study 1}

\section{METHOD}

\section{Participants}

The sample consisted of 1,496 undergraduate students from a large Midwestern university, including 535 freshman, 273 sophomores, 356 juniors, and 329 seniors, with 3 students not reporting classification. The sample included 600 men and 891 women, with 5 participants not reporting gender. The mean age of participants was $20.6 \mathrm{yr}$. $(S D=3.2)$, and mean grade point average (GPA) was $3.29(S D=0.47)$.

\section{Materials}

Participants completed the AGQ-R (Elliot \& Murayama, 2008). This 12-item scale (presented in Table 5) is intended to measure mastery-approach goals, mastery-avoidance goals, performance-approach goals, and performance-avoidance goals with three items on each subscale. All items were measured at the class level (i.e., were asked about "this class"), to provide a context specific-rather than domain-general measurement. Also included was a demographic questionnaire that asked participants for age, gender, ethnicity, college classification, and GPA.

\section{Procedure}

Volunteers were recruited from a total of 92 undergraduate classes spanning all academic areas at the University for paper-based data collection. All surveys were administered during the class period. A researcher informed students of the purposes of the study, and any students who did not wish to participate were asked to return their packet blank. Participants returned the completed survey directly to the researcher, who remained in the room. No inducement was offered for participation, but near total participation was 
observed in all classes recruited. All participants were treated in accordance with APA ethical guidelines, and the procedures were approved by the university's Institutional Review Board.

\section{RESULTS}

In the present study, the correlation matrix was factored using principal axis factoring. The KaiserMeyer-Olkin measure of sampling adequacy was high $(\mathrm{KMO}=0.847)$ and Bartlett's test of sphericity was significant $\left(\chi_{66}^{2}=7440.09, p<.001\right)$ indicating a factorable matrix. The initial eigenvalues suggested a three-factor solution using either the K-1 rule or Cattell's scree test (Fig. 1). Three factors had eigenvalues exceeding 1.0, and there was a steep dropoff in the scree plot following the third factor, and the first three factors cumulatively accounted for $65.75 \%$ of the total variance in the system, all of which suggested a three-factor solution. Table 1 presents a list of the initial eigenvalues with variance explained. Given the disparity in the literature on the number of factors that should be extracted from this instrument, Horn's (1965; Zwick \& Velicer, 1986) parallel analysis was also used to test the correct number of factors to extract (Fig. 2). According to the parallel analysis, following the third factor, the actual extraction eigenvalues fall well below the mean and percentile value of the values extracted from random data. As delineated below, the theoretical meaningfulness of the three-factor solution was also satisfying. Therefore, the three-factor solution was rotated.

Because the factors were expected to be correlated, direct oblimin rotation with Kaiser normalization was used. The pattern and structure coefficients for the resulting factors can be found in Table 2. These factors were moderately correlated (Factor 1 with Factor 2, $r=.35$; Factor 1 with Factor 3, $r=.31$; Factor 2 with Factor $3, r=.17$ ). A .40 cutoff was used in identifying salient loadings. Items cross-loading above .40 on more than one factor were dropped from the final interpretation. As a result, Items 2, 4, 6, 8, 10, and 12 significantly loaded on Factor 1, and this factor was interpreted as Performance. Items 1, 2, 3, and 7 significantly loaded on Factor 2, which was interpreted as Mastery-Approach. Items 5, 6, 9, 10, and 11 were significantly loaded on Factor 3, which was interpreted as Mastery-Avoidance. Descriptive statistics and inter-item correlations can be found in Table 3.

\section{DISCUSSION}

In this sample, the data clearly indicated a three-factor structure. Based on the theoretical content of the items in that structure, it appears that the performance items failed to differentiate into two distinct factors of approach and avoidance. Further, in this sample, the structure did support the distinction of masteryapproach and mastery-avoidance. However, most previous studies on the AGQ-R have utilized confirmatory methods. As a result, a new sample was gathered for confirmatory factor analysis of the structure revealed by the exploratory factor analysis.

\section{Study 2}

\section{Participants}

Participants for this study were undergraduate students from a large Midwestern university currently enrolled in face-to-face classes. They were recruited through emails to their student email accounts, which were distributed to 5,000 randomly selected students. A total of 1,125 students participated. The sample included 370 men and 750 women, with five not reporting gender. In terms of college classification, there were 258 freshman, 261 sophomores, 285 juniors, and 299 seniors in the sample, with 22 reporting "other" as their college classification. The mean age was $21.7 \mathrm{yr}$. $(S D=5.4)$ and mean GPA was $3.36(S D=0.58)$. 


\section{Measures}

As in Study 1, participants completed the AGQ-R (Elliot \& Murayama, 2008), as well as a demographic questionnaire, which asked for age, gender, ethnicity, college classification, college major, and GPA. As in Study 1, measures were phrased in a context specific manner (i.e., "this class") but participants were instructed to think about and describe a particular class prior to beginning the quantitative measures.

\section{Procedure}

Emails were sent with information about the study and a link to the online survey to 5,000 randomly selected students. After reading the consent form and agreeing to participate, the AGQ-R was then administered, and participants were offered the chance to enter into a lottery comprised of four $\$ 50.00$ cash prizes as an incentive for their participation. The university's Institutional Review Board approved these procedures, and all participants were treated in compliance with APA ethical standards.

\section{RESULTS}

First, a maximum likelihood confirmatory factor analysis was performed on the Achievement Goal Questionnaire with three factors as specified in the exploratory analysis undertaken in Study 1. The items loaded on the three factors were determined by those items that loaded cleanly on one factor with a loading above .40. Any cross-loading items (items loading on more than one factor above .40) or items not loading on any factor were excluded from the confirmatory model. This resulted in three factors interpreted as Mastery-Approach (Items 1, 3, and 7), Mastery-Avoidance (Items 5 and 9), and Performance (Items 6, 8, and 12). This model (Model 1) was a reasonably good fit to the observed data, though the chisquared/degrees of freedom ratio was large $\left(\chi_{17}^{2}=190.18, \chi^{2} / d f=11.19, \mathrm{GFI}=0.97, \mathrm{CFI}=0.95\right.$, RMSEA $=0.08$ ). Standardized factor loadings and variances are presented in Table 3. This proposed alternative model was then compared with a number of potentially competing models including:

Model 2. A model including only two factors, defined as Mastery (Items 1, 3, 5, 7, 9, and 11), and Performance (Items 2, 4, 6, 8, 10, and 12). This model was tested because it is a historically competing model where motivational valence is not differentiated. This model was a poor fit to the data $\left(\chi^{2}{ }_{53}=2020.92\right.$, $\chi^{2} / d f=38.13, \mathrm{GFI}=0.71, \mathrm{CFI}=0.70, \mathrm{RMSEA}=0.18$ ).

Model 3. A two-factor model including only the approach vs avoidance dimension. This model was tested to determine whether motivational valence alone would provide a good fit to the observed data. The two factors were Approach (Items 1, 2, 3, 4, 7, and 8) and Avoidance (Items 5, 6, 9, 10, 11, and 12). This model was also a poor fit to the data $\left(\chi^{2}{ }_{53}=1903.76, \chi^{2} / d f=35.92, \mathrm{GFI}=0.73, \mathrm{CFI}=0.72, \mathrm{RMSEA}=0.18\right)$.

Model 4. A three-factor model including a generalized Mastery factor (Items 1, 3, 5, 7, 9, and 11), Performance-Approach (Items 2, 4, and 8), and Performance Avoidance (Items 6, 10 and 12). This was to test whether the differentiation of valence was necessary on mastery or if a generalized factor would fit the data. Additionally, theorists have questioned the validity of the Mastery-Avoidance construct, and this is one possible way of addressing those concerns through the creation of a generalized Mastery factor. This model, however, was not a good fit to the data $\left(\chi^{2}{ }_{51}=1463.68, \chi^{2} / d f=28.70, \mathrm{GFI}=0.81, \mathrm{CFI}=0.78, \mathrm{RMSEA}=0.16\right)$.

Model 5. A three-factor model was tested with Mastery-Approach (Items 1, 3, and 7), Performance-Approach (Items 2, 4, and 8), and Performance-Avoidance (Items 6, 10, and 12). This was done because of the theoretical debate over the nature and stability of the Mastery-Avoidance construct. In this model all three other subscales maintained their original structure and the potentially controversial Mastery-Avoidance subscale was removed altogether. This model was a good fit to the data, with the exception of the large chisquare to degrees of freedom ratio $\left(\chi^{2} 24=249.24, \chi^{2} / d f=10.39, \mathrm{GFI}=0.95, \mathrm{CFI}=0.96\right.$, RMSEA $\left.=0.09\right)$.

Model 6. A four-factor model as proposed by Elliot and Murayama (2008). This model included MasteryApproach (Items 1, 3, and 7), Mastery-Avoidance (Items 5, 9, and 11), Performance-Approach (Items 2, 4, and 8), and Performance-Avoidance (Items 6, 10, and 12). This model was not a good fit to the data, as 
demonstrated by the large chi-square to degrees of freedom ratio as well as the large RMSEA value $\left(\chi^{2}{ }_{48}=690.78, \chi^{2} / d f=14.38, \mathrm{GFI}=0.91, \mathrm{CFI}=0.90, \mathrm{RMSEA}=0.11\right)$. Because this model is the predominant model in the literature, the factor loadings and variances are provided in Table 6.

Models 2 through 4 were all very poor fits to the data, while Model 5 is nearly the same in terms of fit as the proposed three-factor solution based on the EFA results. The model proposed by Elliot and Murayama (2008) tested in Model 6 also did not present a good fit to the data, and was a worse fit than the proposed model, or Model 5. This means that the EFA produced a model that offered an empirical advantage to that currently in use, and that simply dropping Mastery-Avoidance from the model as was tested in Model 5 also produces a better-fitting model than what is currently in use. Descriptive statistics and inter-item correlations can be found in Table 7.

\section{DISCUSSION}

The confirmatory factor analyses show that there are two models that are essentially equivalent in their fit to the observed data. Both of these models are three-factor models rather than the four-factor model proposed by Elliott and Murayama (2008). In one, performance goals are generalized while allowing for mastery-approach goals and mastery-avoidance goals to be measured independently. In the second, masteryapproach goals, performance-approach goals, and performance-avoidance goals are all measured, but the items for mastery-avoidance are completely eliminated from the measurement model. Because the fit of the two models is so close, the decision should be theoretical.

\section{GENERAL DISCUSSION}

The exploratory factor analysis in Study 1 indicated a generalized performance factor with differentiation of mastery-approach and mastery-avoidance. Thus, following the exploratory factor analysis, one might choose the model with mastery-approach goals, mastery-avoidance goals, and performance approach goals. Yet, there is a history in the achievement goal literature for favoring the differentiation (on motivational valence) of performance goals over the differentiation of mastery goals. One potential conclusion could be that the current measurement model of the AGR-R does not support a full four-factor model under factor analytic examination, but that the distinction could be potentially valid for both mastery and performance goals given appropriate items.

Theorists in the area of achievement goals have been divided on the issue of mastery-avoidance goals. Although those goals did emerge as their own factor in the exploratory model, this factor is empirically weak in the confirmatory model, having only two items. Additionally, that model is almost identical in fit to a model where mastery-avoidance is removed altogether while the other three goal-types are retained. This may indicate that mastery-avoidance goals present not only a theoretical challenge, but an empirical one as well. One possibility is that they are difficult to measure. Anecdotally, students report difficulty with responding to the mastery-avoidance items on the AGQ-R. Their difficulty in responding to the items could indicate some problem with the wording of the items, causing them to fail to adequately measure the latent construct of mastery-avoidance goals. However, it is also possible that the difficulty in writing good items for mastery-avoidance stems from a larger issue with the theoretical construct; i.e., the latent factor of 'mastery-avoidance goals' may not exist as it is currently conceptualized.

Of particular note, the theorizing of mastery-avoidance goals originated in and has been concentrated on academic contexts. For example, the seminal and governing definitions include the avoidance of not learning, or a focus on not misunderstanding (Elliot, 1999). This becomes a definitional issue wherein the very construct is academically construed. Achievement goals, though, are not theoretically constrained to any particular domain. In fact, Elliot (2005) states that achievement goals are applicable to all "achievement situations, such as the classroom, the workplace, and the ballfield," (p. 52) yet goes on to describe them almost exclusively in terms of academic achievement and classroom contexts. In other words, it could be the case that the theory functions differently, perhaps better, in other domains. Achievement goal theory has been used in sports psychology, and the AGQ revised for that use. In one study, the AGQ-S (revised for sports applications) seemed to show a much stronger mastery-avoidance factor than in academic contexts 
(Conroy, Elliot, \& Hofer, 2003). Although the AGQ-S is not the focus of the present study, the findings are nonetheless interesting. Whether it is the context or new item wordings that made the difference, it appears that under the right conditions, it may be possible to measure mastery avoidance. What appears clear is that AGQ-R does not do so.

The implications of the present study, necessarily, only extend as far as the measurement model of the AGQ-R. That is, these factor analytic results do not necessarily speak to the nature of achievement goals as a theoretical construct. As demonstrated by the apparent adequacy of mastery-avoidance in the AGQ-S (Conroy, Elliot, \& Hofer, 2003), it may be that academic contexts are not well-suited to the formation of mastery-avoidance goals. Of course, it is also possible that the AGQ-R simply does not measure such goals well. Mastery-avoidance goals may also not as a separable construct from mastery-approach goals (as in the trichotomous model). It is worth noting that the construct of mastery avoidance did not arise out of theoretical necessity or a framework in which it was logically placed, but rather because it replaced a trichotomous model with a more symmetrical four-factor model. Perhaps this drive for symmetry and a more conceptually appealing model resulted in a model with one latent construct that does not exist. The other possibility is that it is simply a measurement issue. In other words, perhaps the theoretical constructs do not need to be modified based on factor analytic results, but instead factor analytic results point to an imprecision in the measurement of those theoretical constructs in the present measurement methodology. Either of these possibilities points to a need to refine and improve the way achievement goals are measured in the field, and a need for caution on the part of researchers using the AGQ-R as a measure of achievement goals.

The AGQ-R presents some potential limitations on the face. For example, particularly in the case of mastery-avoidance, the items are so similar as to be virtually identical. They involve synonyms and syntax reversals, but no real content shifts as one would expect to gain additional domain coverage. This leads one to wonder if the construct is really so simple as to be measured in three nearly identical items, or if a more complex measurement is necessary. Additional items might lead to increased content validity as well as an improved measurement model allowing the factors to be more easily separated, assuming that separable constructs exist.

The present study has limitations. First, the sampling methodology used included only undergraduate college students at a state university in the Midwest. Students outside this context may vary in their perceptions of goals, and thus the structure of the instrument may vary in other contexts. However, the present sample is similar to those used in previous work, which has focused almost exclusively on undergraduate student populations. Thus, although there is no reason to suspect the present samples vary greatly from those used in prior studies on the AGQ-R, the sample does limit the generalizability of the findings. Another possible limitation of the present study is that it was constrained to the original AGQ-R items. It is possible that one of the issues with measurement is the fact that the AQR-R itself is too limited in measurement by using only three items per construct to measure what are undoubtedly nuanced and complex latent constructs.

Future research should go beyond the structure of the instrument into the validity and utility of the underlying constructs. There are a wide range of structural and factor analytic studies available now on the AGQ-R, so future research would be served by focusing on the way that factor scores are useful (or not) in discriminant and predictive analyses. These kinds of analyses will contribute additional information to understanding which factor structures give the best understanding of other variables of interest such as academic motivation and student classroom behaviors.

\section{REFERENCES}

Ames, C. (1992) Classrooms: goals, structures, and student motivation. Journal of Educational Psychology, 84(3), $261-271$.

Attenweiler, W. J., \& Moore, D. (2006) Goal orientations: two, three, or more factors? Educational and Psychological Measurement, 66(2), 342-352.

Campbell, H. L., Barry, C. L., Joe, J. N., \& Finney, S. J. (2008) Configural, metric, and scalar invariance of the modified achievement goal questionnaire across African American and white university students. Educational and Psychological Measurement, 68(6), 988-1007. 
Conroy, D. E., Elliot, A. J., \& Hofer, S. M. (2003). A 2x2 achievement goals questionnaire for sport: Evidence for factorial invariance, temporal stability, and external validity. Sport Psychology, 25, 456-476.

Donnellan, M. B. (2008) A psychometric evaluation of two achievement goal inventories. Educational and Psychological Measurement, 68(4), 643-658.

Elliot, A. J. (1999) Approach and avoidance motivation and achievement goals. Educational Psychologist, 34(3), 169-189.

Elliot, A. J. (2005) A conceptual history of the achievement goal construct. In A. J. Elliot \& C. S. Dweck (Eds.) Handbook of competence motivation (pp. 52-72). New York, NY: Guilford.

Elliot, A. J., \& Church, M. A. (1997) A hierarchical model of approach and avoidance achievement motivation. Journal of Personality and Social Psychology, 72(1), 218-232.

Elliot, A. J., \& McGregor, H. A. (2001) A 2 x 2 achievement goal framework. Journal of Personality and Social Psychology, $80(3), 501-519$.

Elliot, A. J., \& Murayama, K. (2008) On the measurement of achievement goals: critique, illustration, and application. Journal of Educational Psychology, 100(3), 613-628.

Elliot, A. J., \& Thrash, T. M. (2001) Achievement goals and the hierarchical model of achievement motivation. Educational Psychology Review, 13(2), 139-156.

Finney, S. J., Pieper, S. L., \& Barron, K. E. (2004) Examining the psychometric properties of the achievement goal questionnaire in a general academic context. Educational and Psychological Measurement, 64(2), 365-382.

Grant, H., \& Dweck, C. S. (2003) Clarifying achievement goals and their impact. Journal of Personality and Social Psychology, 85(3), 541-553.

Horn, J. L. (1965) A rationale and test for the number of factors in factor analysis. Psychometrika, 30, 179-185.

Remedios, R., Kiseleva, Z., \& Elliott, J. (2008) Goal orientations in Russian university students: from mastery to performance? Educational Psychology, 28(6), 677-691.

Zwick, W. R., \& Velicer, W. F. (1986) Factors influencing five rules for determining the number of components to retain. Psychological Bulletin, 99, 432-442.

Accepted

TABLE 1

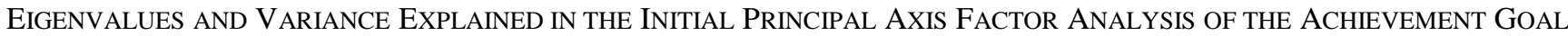
QUESTIONNAIRE, REVISED

\begin{tabular}{lrrr} 
Factor & Eigenvalue & $\begin{array}{c}\text { \% Variance } \\
\text { Explained }\end{array}$ & $\begin{array}{c}\text { Cumulative } \\
\text { \% Variance } \\
\text { Explained }\end{array}$ \\
\hline 1 & 4.62 & 38.52 & 38.52 \\
2 & 1.72 & 14.31 & 52.83 \\
3 & 1.55 & 12.93 & 65.75 \\
4 & 0.86 & 7.20 & 72.95 \\
5 & 0.58 & 4.85 & 77.80 \\
6 & 0.48 & 4.03 & 81.83 \\
7 & 0.43 & 3.61 & 85.43 \\
8 & 0.41 & 3.43 & 88.86 \\
9 & 0.36 & 2.99 & 91.85 \\
10 & 0.35 & 2.90 & 94.75 \\
11 & 0.33 & 2.72 & 97.47 \\
12 & 0.30 & 2.53 & 100.00 \\
\hline
\end{tabular}




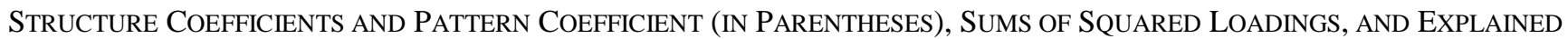
VARIANCE FOR A ROTATED THREE-FACTOR SOLUTION

\begin{tabular}{|c|c|c|c|c|c|}
\hline Item & Factor 1 & Factor 2 & Factor 3 & $h^{2}$ & Theoretical Scale \\
\hline 1 & $.29(-.01)$ & $.79(.77)$ & $.20(.07)$ & 0.62 & Mastery-approach \\
\hline 2 & $.69(.64)$ & $.53(.35)$ & $.04(-.22)$ & 0.62 & Performance-approach \\
\hline 3 & $.28(-.01)$ & $.77(.76)$ & $.21(.09)$ & 0.60 & Mastery-approach \\
\hline 4 & $.73(.72)$ & $.39(.17)$ & $.09(-.16)$ & 0.57 & Performance-approach \\
\hline 5 & $.21(-.04)$ & $.23(.13)$ & $.66(.65)$ & 0.45 & Mastery-avoidance \\
\hline 6 & $.60(.55)$ & $.15(-.09)$ & $.42(.27)$ & 0.43 & Performance-avoidance \\
\hline 7 & $.33(.05)$ & $.71(.67)$ & $.26(.13)$ & 0.52 & Mastery-approach \\
\hline 8 & $.75(.74)$ & $.38(.14)$ & $.11(-.14)$ & 0.59 & Performance-approach \\
\hline 9 & $.31(.06)$ & $.24(.09)$ & $.77(.74)$ & 0.60 & Mastery-avoidance \\
\hline 10 & $.69(.66)$ & $.13(-.15)$ & $.43(.26)$ & 0.55 & Performance-avoidance \\
\hline 11 & $.40(.19)$ & $.36(.22)$ & $.52(.42)$ & 0.37 & Mastery-avoidance \\
\hline 12 & $.77(.77)$ & $.15(-.15)$ & $.39(.17)$ & 0.64 & Performance-avoidance \\
\hline SSL & 3.56 & 2.59 & 1.98 & & \\
\hline$\%$ Variance & 29.69 & 21.55 & 16.51 & & \\
\hline$\%$ Covariance & 43.83 & 31.81 & 34.37 & & \\
\hline
\end{tabular}

TABLE 3

DESCRIPTIVE STATISTICS AND INTER-ITEM CORRELATIONS FOR STUDY 1

\begin{tabular}{lccccc} 
Variable & $M$ & $S D$ & 1. & 2. & 3. \\
\hline 1. Mastery Approach & 5.44 & 1.13 & & & \\
2. Mastery Avoidance & 4.61 & 1.42 & .38 & & \\
3. Performance Approach & 5.51 & 1.18 & .44 & .25 & \\
4. Performance Avoidance & 5.25 & 1.38 & .23 & .46 & .58 \\
\hline
\end{tabular}

Note.-All correlations are significant at $p<.01$.

TABLE 4

STANDARDIZED FACTOR LOADINGS AND VARIANCES FOR A THREE-FACTOR MODEL OF MASTERY-APPROACH, MASTERYAVOIDANCE, AND PERFORMANCE

\begin{tabular}{lrr}
\hline Item & Loading & Variance \\
\hline Mastery-Approach & & 1.05 \\
1. My aim is to completely master the material presented in this class. & 0.78 & 0.78 \\
3. My goal is to learn as much as possible in this class. & 0.75 & 0.64 \\
7. I am striving to understand the content of this course as thoroughly as possible. & 0.76 & 0.75 \\
Performance & 0.65 & 1.44 \\
6. My goal is to avoid performing poorly compared to others in class. & 0.65 & 1.68 \\
8. My goal is to perform better than the other students in this class. & 0.79 & 0.88 \\
12. My aim is to avoid doing worse than other students in this course. & 0.68 & 2.79 \\
Mastery-Avoidance & 0.90 & 1.91 \\
5. My aim is to avoid learning less than I possibly could in this course. & 0.62 \\
9. My goal is to avoid learning less than it is possible to learn in this class. &
\end{tabular}




\begin{tabular}{|c|c|c|c|c|c|c|}
\hline 1. Proposed 3-factor model & 190.18 & 17 & 11.19 & 0.97 & 0.95 & 0.08 \\
\hline 2. Mastery vs Performance 2-factor model & 2020.92 & 53 & 38.13 & 0.71 & 0.70 & 0.18 \\
\hline 3. Approach vs Avoidance 2-factor model & 1903.76 & 25 & 35.92 & 0.73 & 0.72 & 0.18 \\
\hline $\begin{array}{l}\text { 4. 3-factor Model with Mastery, Performance Approach, and Performance } \\
\text { Avoidance }\end{array}$ & 1463.68 & 51 & 28.70 & 0.81 & 0.78 & 0.16 \\
\hline $\begin{array}{l}\text { 5. 3-factor Model with Mastery Approach, Performance Approach, and } \\
\text { Performance Avoidance }\end{array}$ & 249.24 & 24 & 10.39 & 0.95 & 0.96 & 0.09 \\
\hline 6. 4-factor model as proposed by Elliot and Murayama (2008) & 690.08 & 48 & 14.38 & 0.91 & 0.90 & 0.11 \\
\hline
\end{tabular}

TABLE 6

STANDARDIZED FACTOR LOADINGS AND VARIANCES FOR THE FOUR-FACTOR MODEL AS PROPOSED By ELLIOT AND MURAYAMA (2008)

\begin{tabular}{lcc}
\hline Item & Loading & Variance \\
\hline Mastery-Approach & 0.77 & 0.91 \\
1. My aim is to completely master the material presented in class. & 0.81 & 0.55 \\
3. My goal is to learn as much as possible in class. & 0.82 & 0.53 \\
7. I am striving to understand the content of this course as thoroughly as possible. & 0.64 \\
Mastery-Avoidance & 0.74 & 1.62 \\
5. My aim is to avoid learning less than I possibly could in this course. & 0.85 & 0.94 \\
9. My goal is to avoid learning less than it is possible to learn in this class. & 0.50 & 1.90 \\
11. I am striving to avoid an incomplete understanding of the course material. & & 1.40 \\
Performance-Approach & 0.81 & 0.58 \\
2. I am striving to do well compared to other students in this course. & 0.82 & 0.61 \\
4. My aim is to perform well relative to other students in this class. & 0.80 & 0.82 \\
8. My goal is to perform better than the other students in this class. & 0.66 & 1.70 \\
Performance-Avoidance & 0.85 & 0.77 \\
6. My goal is to avoid performing poorly compared to others in class. & 0.82 & 0.83 \\
10. I am striving to avoid performing worse than others in this class. & \\
12. My aim is to avoid doing worse than other students in this course. &
\end{tabular}

TABLE 7

DESCRIPTIVE STATISTICS AND INTER-ITEM CORRELATIONS FOR STUDY 2

\begin{tabular}{lccccc} 
Variable & $M$ & $S D$ & 1. & 2. & 3. \\
\hline 1. Mastery Approach & 5.56 & 1.17 & & & \\
2. Mastery Avoidance & 4.52 & 1.43 & .32 & & \\
3. Performance Approach & 5.61 & 1.21 & .48 & .22 & \\
4. Performance Avoidance & 5.18 & 1.44 & .22 & .49 & .57 \\
\hline
\end{tabular}

Note.-All correlations are significant at $p<.01$. 


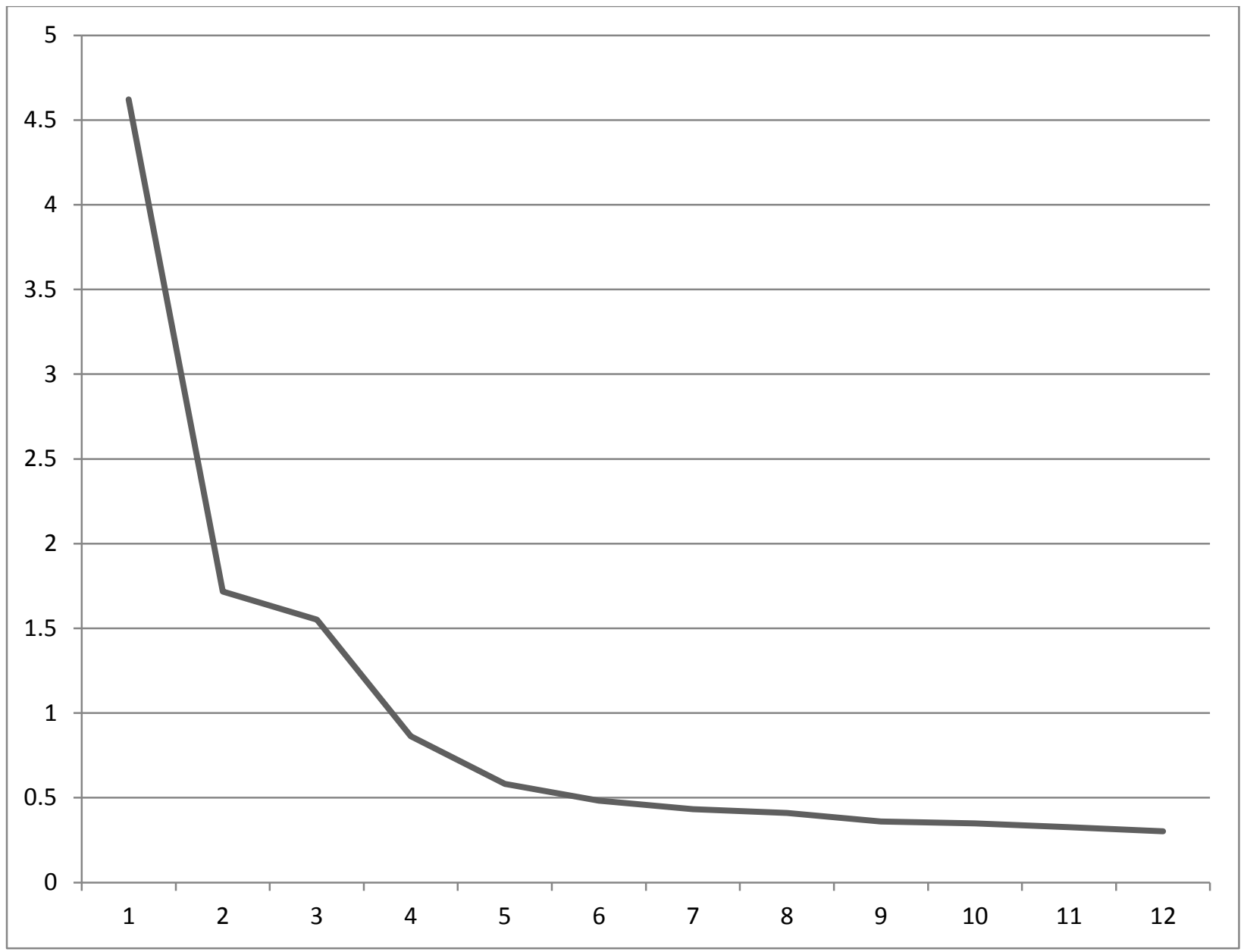

Figure 1 Scree Plot for Principal Axis Factor Analysis of Achievement Goal Questionnaire, Revised. X axis is factor number and $\mathrm{Y}$ axis is eigenvalues.

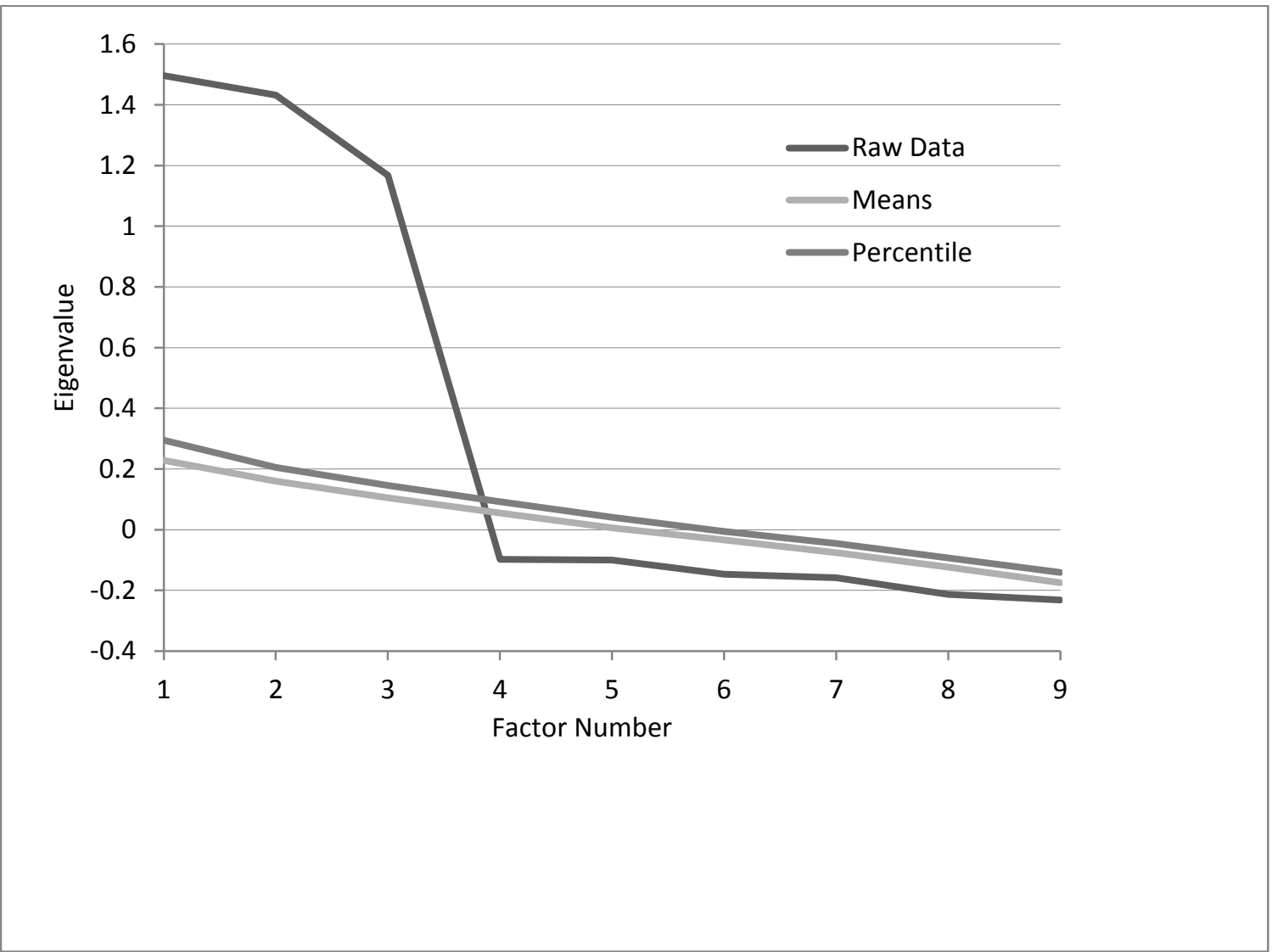

Figure 2 Horn's Parallel Analysis for Achievement Goal Questionnaire, Revised. 